\title{
Micro-deformation behavior in micro-compression with high-purity aluminum processed by ECAP
}

\author{
Jie $\mathrm{Xu}^{1,2,{ }^{*}}$, Chenxi $\mathrm{Wang}^{1}$, Debin $\mathrm{Shan}^{1}$, Bin Guo ${ }^{1,2}$, and Terence G. Langdon ${ }^{3,4}$ \\ 1 Key Laboratory of Micro-systems and Micro-structures Manufacturing of Ministry of Education, Harbin Institute of Technology, \\ Harbin 150080, P.R. China \\ 2 Academy of Fundamental and Interdisciplinary Sciences, Harbin Institute of Technology, Harbin 150080, P.R. China \\ 3 Departments of Aerospace \& Mechanical Engineering and Materials Science, University of Southern California, Los Angeles, \\ CA 90089-1453, USA \\ ${ }^{4}$ Materials Research Group, Faculty of Engineering and the Environment, University of Southampton, Southampton SO17 1BJ, UK
}

Received 21 January 2015 / Accepted 9 February 2015

\begin{abstract}
Ultrafine-grained (UFG) materials have a potential for applications in micro-forming since grain size appears to be the dominant factor which determines the limiting size of the geometrical features. In this research, high-purity Al was processed by equal-channel angular pressing (ECAP) at room temperature through 1-8 passes. Analysis shows that processing by ECAP produces a UFG structure with a grain size of $\sim 1.3 \mu \mathrm{m}$ and with microhardness and microstructural homogeneity. Micro-compression testing was carried out with different specimen dimensions using the annealed sample and after ECAP processing through 1-8 passes. The results show the flow stress increases significantly after ECAP processing by comparison with the annealed material. The flow stress generally reaches a maximum value after 2 passes which is consistent with the results of microhardness. The flow stress decreases with decreasing specimen diameter from $4 \mathrm{~mm}$ to $1 \mathrm{~mm}$ which demonstrates that size effects also exist in the ultrafine-grained materials. However, the deformation mechanism in ultrafine-grained pure Al changes from strain strengthening to softening by dynamic recovery by comparison with the annealed material.
\end{abstract}

Key words: micro-deformation, aluminum, ECAP, micro-forming, ultrafine grains

\section{Introduction}

With the rapid development of micro-electromechanical systems (MEMS), micro-parts are now becoming widely used in the field of microelectronic components [1]. Considerable research has been conducted with micro-forming technologies which offer the advantage of mass production with controlled quality and low cost [2-4]. As in conventional superplasticity, the widely accepted deformation mechanism in the microforming of polycrystalline metals is grain boundary sliding and grain rotation [5]. Therefore, the grain size appears to be the dominant factor which determines the limiting size of the geometrical features that may be fabricated by micro-forming and this means that very small grain sizes, and especially materials having ultrafine grain sizes, are attractive for use in microforming operations.

By comparison with conventional coarse-grained (CG) materials, ultrafine-grained (UFG) materials have a potential

*e-mail: xjhit@hit.edu.cn application in micro-forming due to the high forming quality and good mechanical properties. Thus, recent research also demonstrated a potential for using UFG materials for applications in micro-forming at elevated temperatures [6]. For example, an investigation of micro-extrusion of ultrafine-grained copper shows that UFG materials are beneficial for the microforming process and scatter and uneven shape evolution can be reduced compared to the conventional CG materials [7]. However, only very limited information is at present available on the micro-deformation behavior when the material grain size is reduced to the submicrometer level although these problems and their inherent limitations are beginning to attract attention within the materials science community [8-12]. There is an important shortcoming at the present time because only limited information is available on the micro-scale deformation behavior of UFG materials after processing by ECAP although this information is critically needed for the effective utilization of these materials in micro-forming technologies. In this study, micro-deformation behavior in micro-compression with pure Al processed by ECAP was investigated. 

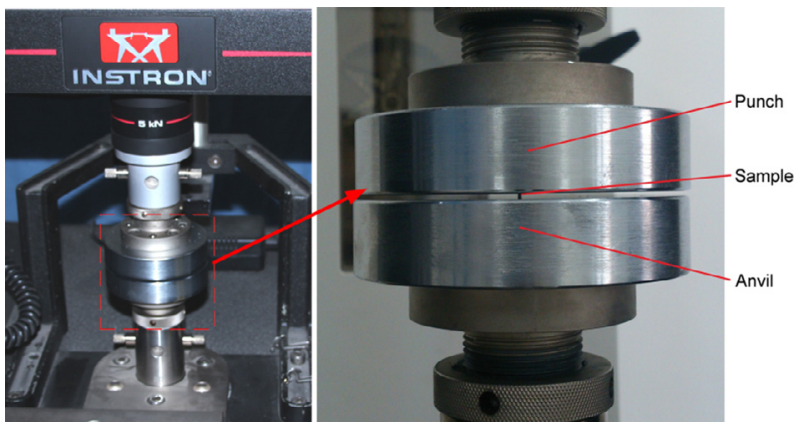

Figure 1. The micro-compression platform.

\section{Experimental materials and parameters}

The experiments were conducted using a very high purity (99.999\%) aluminum supplied in the form of drawn rods having diameters of $10 \mathrm{~mm}$ and lengths of $\sim 70 \mathrm{~mm}$. An annealing treatment was performed on the aluminum billets at a temperature of $773 \mathrm{~K}$ for $1 \mathrm{~h}$ to obtain an initial grain size of $\sim 300 \mu \mathrm{m}$. The ECAP processing was conducted at room temperature using a die with an internal angle of $90^{\circ}$ between the two parts of the channel and an outer arc of curvature of $20^{\circ}$ at the point of intersection. All billets were pressed using processing route $B_{c}$ in which the billets are rotated in the same direction by $90^{\circ}$ around the longitudinal axis between each pass [13]. For these experiments, the billets were sprayed with an $\mathrm{MoS}_{2}$ lubricant and processed for 1, 2, 4 and 8 passes. Further details on ECAP processing are provided elsewhere [14].

For measurements of the Vickers microhardness, $H v$, small disks with thicknesses of $\sim 3.0 \mathrm{~mm}$ were cut from the samples processed by ECAP. The microhardness was examined on disks with mirror-like polished surfaces using a Vickers microhardness tester with a load of $50 \mathrm{gf}$ for the annealed high purity aluminum and loads of $100 \mathrm{gf}$ for the ECAP-processed samples with dwell times of $10 \mathrm{~s}$. The microhardness was recorded for all samples along radial directions at distances separated by $0.5 \mathrm{~mm}$. The initial average hardness for the annealed high purity aluminum sample was $H v \approx 20$.

The microstructures of the samples were observed using an FEI Quanta 200FEG field emission scanning electron microscope (FESEM) and the data were analyzed using a TSL OIM system. Samples were prepared for the microstructural observations by slicing the as-pressed billets perpendicular to the pressing direction to give disks having thicknesses of $\sim 3 \mathrm{~mm}$. One side of each disk was ground on $\mathrm{SiC}$ papers and then mechanically polished with $0.5 \mu \mathrm{m}$ diamond paste. Finally, the disks were electro-polished to mirror-like surfaces using a solution of $10 \% \mathrm{HClO}_{4}$ and $90 \% \mathrm{C}_{2} \mathrm{H}_{5} \mathrm{OH}$ with a DC voltage of $35 \mathrm{~V}$ under a temperature of $253 \mathrm{~K}$.

For micro-compression tests, cylinders with diameters of 1 , 2 and $4 \mathrm{~mm}$ and a height-to-diameter ratio of 1.5 were cut from the as-annealed condition and the materials after ECAP processing with the compression axis parallel to the extrusion axis. The micro-compression tests were conducted at room temperature at a strain rate of $1.0 \times 10^{-2} \mathrm{~s}^{-1}$ using an Instron-5965 testing machine as shown in Figure 1.

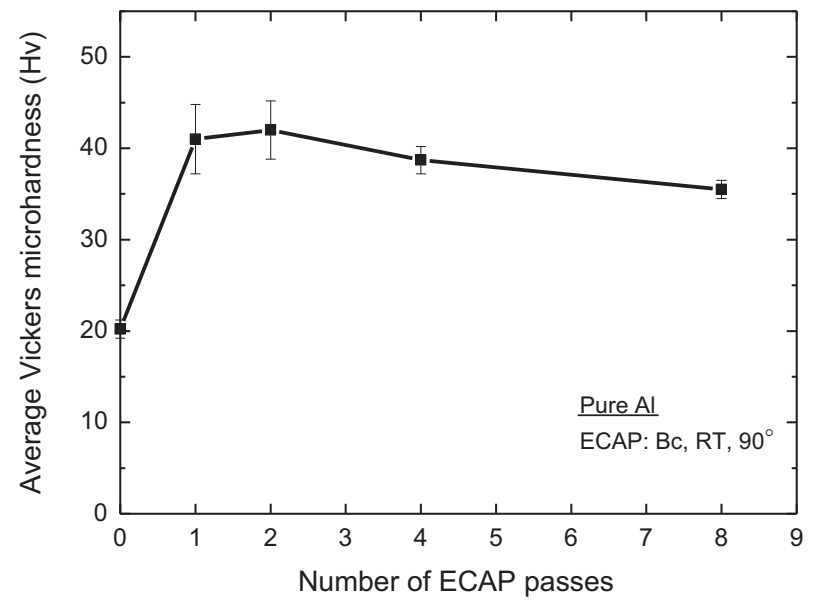

Figure 2. Variation of the average Vickers microhardness with the number of ECAP passes.

\section{Experimental results}

\subsection{Microhardness measurements after ECAP}

The average values of the Vickers microhardness and the standard deviations are shown in Figure 2 for the annealed sample and after processing by ECAP for up to 8 passes. It is apparent from Figure 2 that there is a significant strain softening behavior in pure $\mathrm{Al}$ processed by ECAP. The results demonstrate that the average value of $H v$ increases abruptly from $H v \approx 20$ for the as-annealed condition to $H v \approx 41$ after a single pass of ECAP, then increases further by a very minor amount in the second pass to the maximum value of $H v \approx 42$ and thereafter it decreases slowly to a value of $H v \approx 35.5$ after a total of 8 passes. These results are consistent with an earlier report where it was shown that the hardness values decreased to a minor extent after 2 passes of ECAP for high-purity $\mathrm{Al}$ of $99.99 \%$ purity, whereas there was a continuous but gradual increase in hardness up to 6 passes for an Al-6061 alloy [15]. Further calculations show that the average errors on $H v$ at the standard deviation are 3.8, 3.2, 1.5 and 1.0 after ECAP through 1, 2, 4 and 8 passes, respectively. Thus, the measurements demonstrate that the level of microhardness homogeneity is gradually improved with increasing numbers of ECAP passes.

\subsection{Microstructural evolution after ECAP}

Figure 3 shows the microstructure of high purity aluminum at the initial annealed condition and the materials after ECAP processing, where the grain colors are determined by the orientation of each grain as depicted in the unit triangle. For the annealed material shown in Figure 3a, the grain size was measured as $\sim 300 \mu \mathrm{m}$. Figures $3 \mathrm{~b}-3 \mathrm{e}$ show the OIM images after processing through (b) 1, (c) 2, (d) 4 and (e) 8 passes, respectively. Inspection of Figures $3 \mathrm{~b}$ and $3 \mathrm{c}$ show that some regular arrays of elongated cells which are separated by high-angle boundaries are introduced during ECAP processing through 


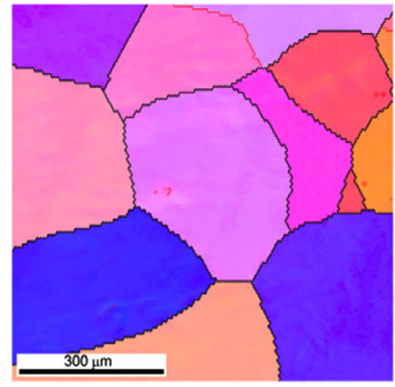

(a)

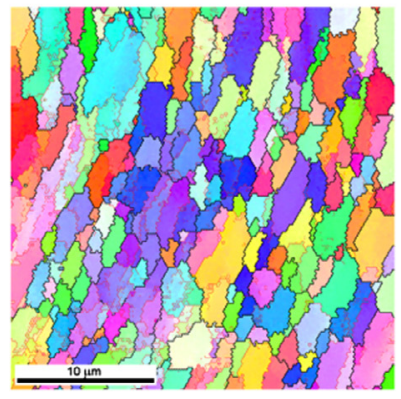

(d)

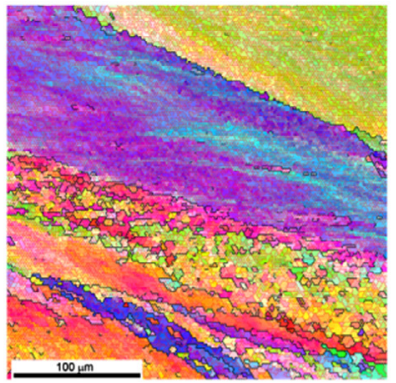

(b)

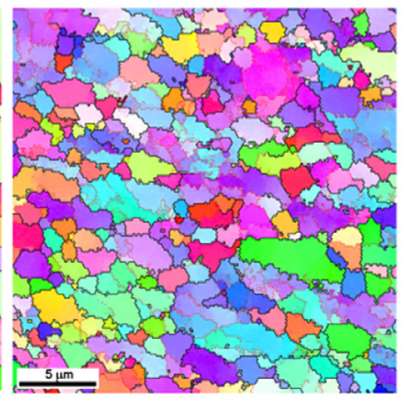

(e)

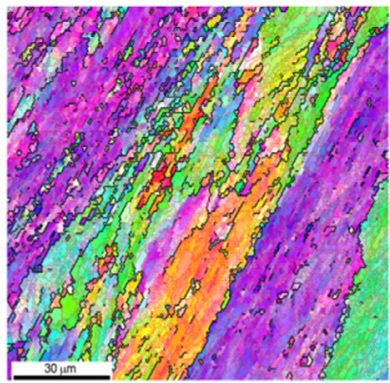

(c)
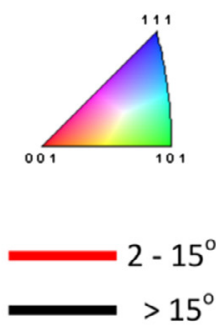

Figure 3. The OIM images for high-purity aluminum in (a) the initial annealed condition and after ECAP through (b) 1 , (c) 2 , (d) 4 and (e) 8 passes using route $\mathrm{B}_{\mathrm{c}}$ at room temperature.
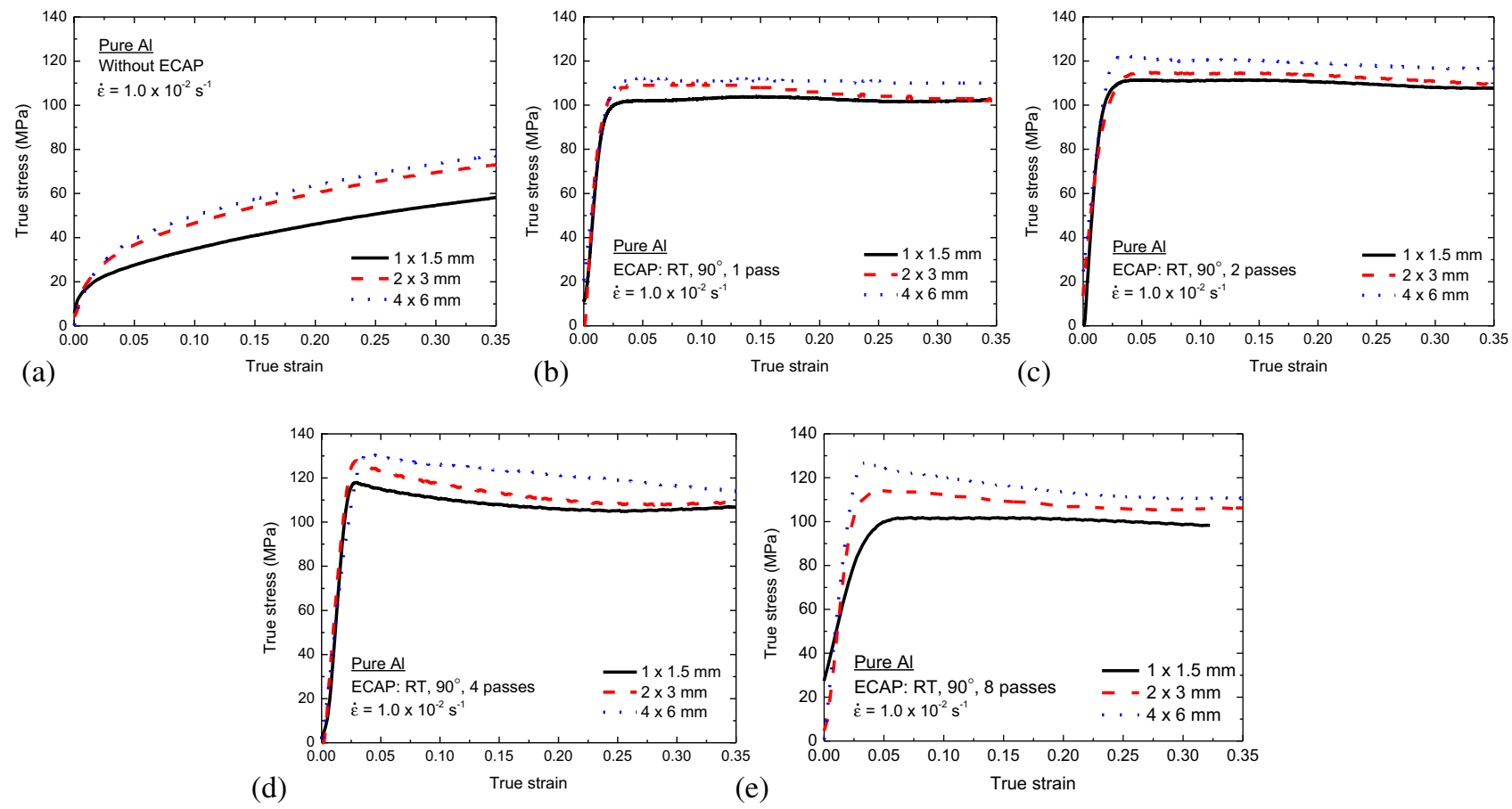

Figure 4. Plots of true stress versus true strain for high-purity aluminum of different specimen sizes (a) without ECAP, (b) 1 pass, (c) 2 passes, (d) 4 passes and (e) 8 passes.

1 and 2 passes. Within these cells, there are many subgrains oriented approximately parallel to each other. This inhomogeneous microstructure is similar to earlier results reported for $\mathrm{Al}$ single crystals [16] and high purity (99.99\%) aluminum [17] processed by ECAP for 1 pass. A regular array of grains is achieved after 4 passes with an average size of $\sim 1.4 \mu \mathrm{m}$ as shown in Figure $3 \mathrm{~d}$ and it is apparent that there is both a significant increase in the numbers of grain boundaries having 


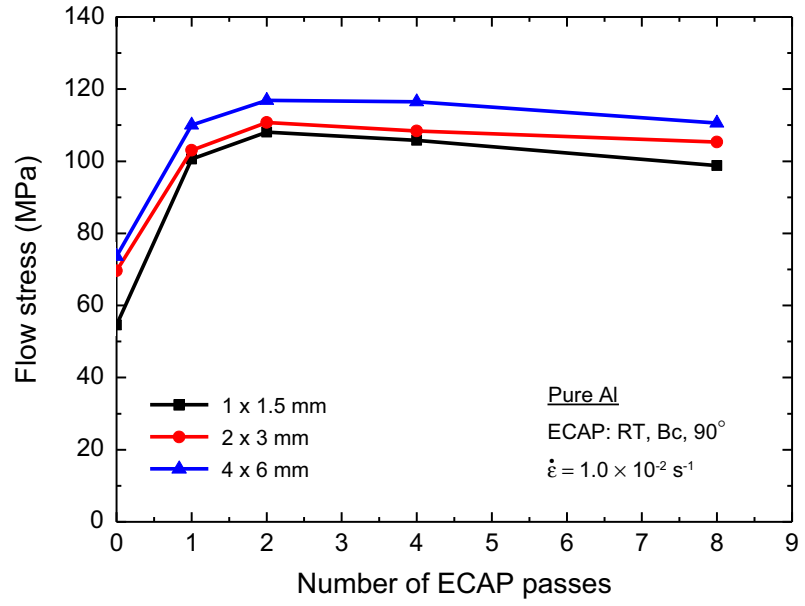

Figure 5. The curves of flow stress with increasing numbers of ECAP passes.

high-angles of misorientation and a greater variation in the colors within the unit triangle between adjacent grains. After ECAP processing through 8 passes, as shown in Figure $3 \mathrm{e}$, there is a fully equiaxed structure with a measured average grain size of $\sim 1.3 \mu \mathrm{m}$ which is consistent with earlier reports for the ECAP processing of aluminum of $99.99 \%$ where the final stable grain size was reported as $\sim 1.3 \mu \mathrm{m}$ $[18,19]$.

\subsection{Micro-compression testing}

The relationship between true stress and true strain is shown in Figure 4 for the annealed samples and specimens processed by ECAP through different numbers of ECAP passes with diameters of 1,2 and $4 \mathrm{~mm}$. The results show that the true stress decreases with decreasing diameter not only for the annealed samples but also for the specimens processed by ECAP which indicates that specimen size effects exist for the ultrafine-grained materials. However, the deformation behavior changes from strengthening for the coarse-grained Al to softening for the pure Al processed by ECAP through 1 pass to 8 passes. In addition, the true stress can be improved significantly after ECAP processing.

Figure 5 shows the relationship between flow stress at true strain of 0.3 and numbers of ECAP passes. For all testing conditions, the flow stress increases dramatically after ECAP processing through 1 pass by a factor of approximately $2 \times$, and then to a maximum value in the second pass. Thereafter, there is a slow decrease after a total 8 passes. These results are consistent with the strain softening behavior of microhardness measurements. In addition, there is a significant decrease in flow stress with decreasing specimen size from $4 \mathrm{~mm}$ to $1 \mathrm{~mm}$ in diameter.

Figure 6 shows the SEM images of surface topography of samples after micro-compression for the annealed pure $\mathrm{Al}$ and ECAP processed pure $\mathrm{Al}$ through different numbers of passes. It can be seen that the surface roughening effect decreases with increasing of ECAP passes compared with the annealed sample. The results also show that the surface quality and profile of the sample processed by ECAP through 8 passes can be improved significantly compared to the annealed pure $\mathrm{Al}$ for all the samples with different specimen dimensions. However, profiles of the compressed sample for the pure $\mathrm{Al}$ processed by ECAP though one and 2 passes are uneven due to the texture after ECAP processing as shown in Figures $3 \mathrm{~b}$ and $3 \mathrm{c}$.

Figure 7 shows the surface topographies of the compressed specimens with different specimen size of $4 \mathrm{~mm}, 2 \mathrm{~mm}$, and $1 \mathrm{~mm}$ in diameter using high-purity $\mathrm{Al}$ after annealing treatment and processing by ECAP through 8 passes. The results show that the geometries of the compressed samples become irregular with decreasing of specimen size, which is caused by the non-uniform deformation on the surface of the compressed specimen. However, the non-uniform deformation can be improved with the UFG pure $\mathrm{Al}$ produced by ECAP through 8 passes. The improvement of non-uniform of the compressed specimens of $4 \mathrm{~mm}$ in diameter is much more significant than that of the compressed specimens of $1 \mathrm{~mm}$ in diameter. Furthermore, the irregular surface can be improved with UFG pure Al for all size specimens as shown in Figures 7d-7f, respectively. In addition, the surface roughness relative to the specimen size increases with decreasing of specimen size.

\section{Discussion}

\subsection{Strain softening behavior during micro-scale deformation in pure Al processed by ECAP}

Based on the microhardness measurements, microstructural observations and micro-compression testing with the sample in the annealed condition and after ECAP processing through different passes, Figure 8 summarizes the strain softening results in high-purity aluminum. In situ recovery plays an important role in microstructural evolution during SPD processing. Furthermore, it is well known that high-purity aluminum has a very high stacking fault energy by comparison with $\mathrm{Cu}$, and it is well established that recovery occurs very easily during ECAP processing [20]. Inspection of the results from Figure 3 for the microstructural evolution in high-purity aluminum processed by ECAP shows the three stages of microdeformation behavior corresponding to an initial stage, a mid stage of hardness and flow stress increase and a strain softening stage, respectively. Figure 3 a shows that the annealed sample with perfect recrystallized grains has lowest microhardness and flow stress after micro-compression. It is apparent from Figures $3 b$ and $3 c$ that the microstructure consists of some regular arrays of elongated cells and there are many subgrains within them. The boundary misorientation is also very low. The accumulation of dislocations and formation of subgrain boundaries leads to a dramatic increase in flow stress after micro-compression in pure $\mathrm{Al}$ processed by ECAP through 1 and 2 passes. In Figures $3 \mathrm{~d}$ and $3 \mathrm{e}$, the subgrain boundaries decrease and the microstructure consists of equiaxed grains 

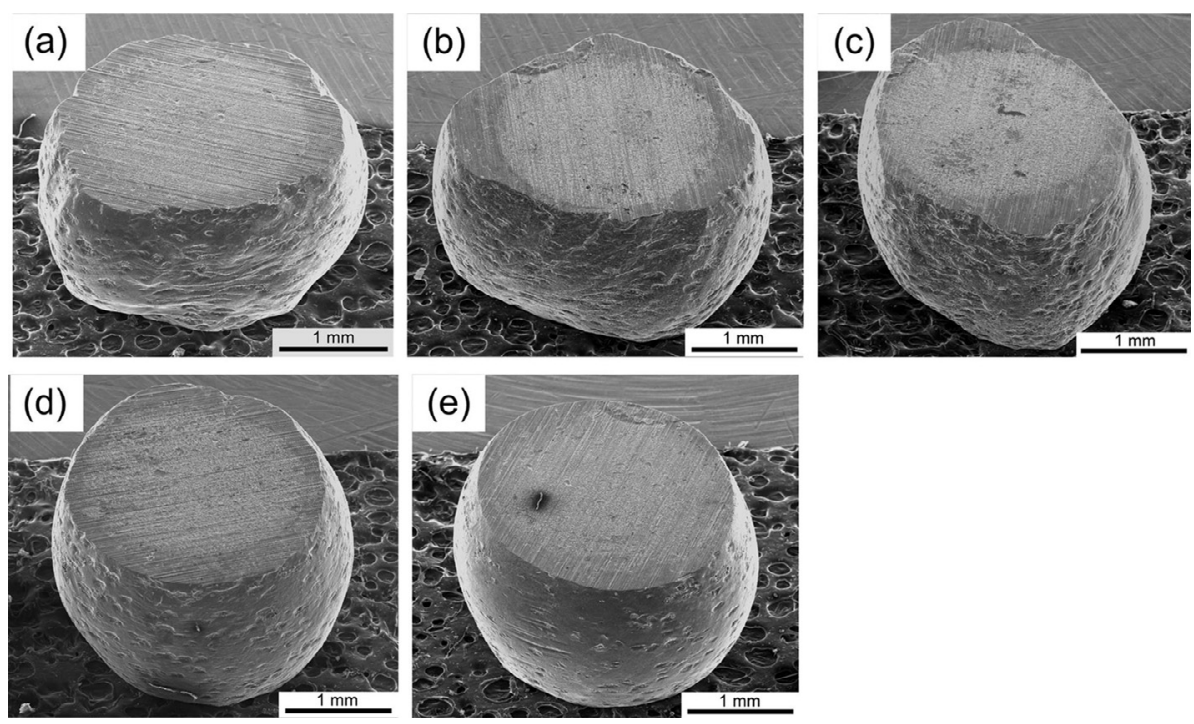

Figure 6. Surface topographies of the compressed specimens for (a) the annealed and ECAP processed pure Al through (b) 1, (c) 2, (d) 4 , and (e) 8 of passes.
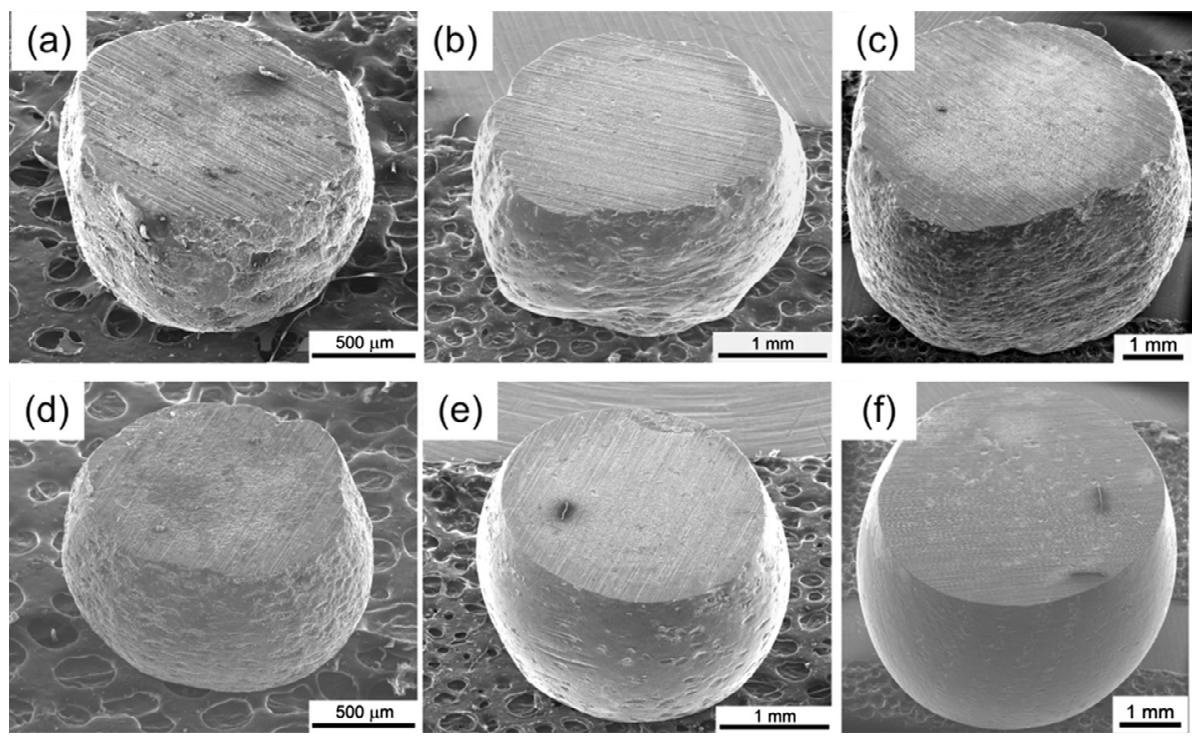

Figure 7. SEM images of the compressed specimens of high-purity Al after annealing treatment (a-c) and processing by ECAP through 8 passes $(\mathrm{d}-\mathrm{f})$ with specimen size of $1,2,4 \mathrm{~mm}$ in diameter.

with high-angle grain boundaries. These results demonstrate the reduction of subgrains and recrystallization are the main reason for strain softening during micro-compression using UFG pure Al.

\subsection{Improvement of surface roughening effect during micro-compression of UFG pure Al}

Inspection of Figures 6 and 7 show the surface topography of the samples after micro-compression with high-purity $\mathrm{Al}$ in the annealed condition and after ECAP processing. It is apparent that the geometries and surface quality of the compressed samples can be improved using UFG pure $\mathrm{Al}$ processed by
ECAP through 8 passes by comparison with the CG pure $\mathrm{Al}$ in the annealed condition. In $\mathrm{CG}$ pure $\mathrm{Al}$, the grain matrix deformation is dominated by shear deformation in the grains and this is significantly affected by the grain orientations. The grain orientation varies and the sliding systems are oriented differently with the compressive direction. The uneven compressive deformation leads to irregular and non-circular profiles due to grain orientation effects at the micro-scale. By contrast, micro-compressive deformation is conducted by grain sliding and rotation and the uneven deformation can be improved due to the microstructural homogeneity in UFG pure Al. These results demonstrate that UFG materials improve the deformation compatibility during micro-forming. In the future, 


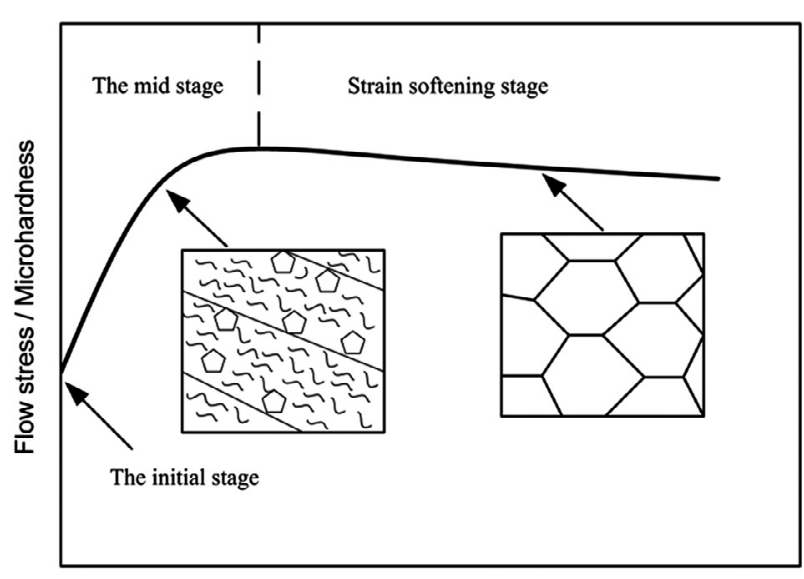

Equivalent strain

Figure 8. Illustration of strain softening behavior with microstructural evolution after micro-compression using high-purity $\mathrm{Al}$ processed by ECAP.

it will be important to conduct an in-depth study of the microdeformation mechanism of UFG high-purity Al.

\section{Conclusions}

1. Ultrafine-grained pure $\mathrm{Al}$ with a grain size of $\sim 1.3 \mu \mathrm{m}$ with microhardness and microstructural homogeneity was achieved after processing by ECAP through 8 passes.

2. The true stress after micro-compression decreases with decreasing diameter of specimen, which indicates that specimen size effects continue to exist for the ultrafinegrained materials. However, the deformation behavior changes from strengthening for the coarse-grained $\mathrm{Al}$ to softening for the pure $\mathrm{Al}$ processed by ECAP through 1 pass to 8 passes.

3. The surface roughening effect decreases with increasing ECAP passes compared with the annealed sample.

Acknowledgements. This work was supported by the National Basic Research Program of China under Grant No. 2012CB934100, by the National Natural Science Foundation of China under Grant
No. 51105102, and by the European Research Council under Grant Agreement No. 267464-SPDMETALS.

\section{References}

1. M. Geiger, M. Kleiner, R. Eckstein, N. Tiesler, U. Engel, CIRP Ann. Manuf. Technol. 50 (2001) 445.

2. F. Vollertsen, H. Schulze Niehoff, Z. Hu, Int. J. Mach. Tools Manuf. 46 (2006) 1172.

3. M.W. Fu, W.L. Chan, Int. J. Adv. Manuf. Technol. 67 (2013) 2411.

4. Y. Qin, A. Brockett, Y. Ma, A. Razali, J. Zhao, C. Harrison, W. Pan, X. Dai, D. Loziak, Int. J. Adv. Manuf. Technol. 47 (2010) 821.

5. Y. Saotome, T. Zhang, A. Inoue, Mater. Res. Soc. Symp. Proc. 554 (1999) 385.

6. J. Xu, M. Shirooyeh, J. Wongsa-Ngam, D. Shan, B. Guo, T.G. Langdon, Mater. Sci. Eng. A 586 (2013) 108.

7. X.G. Qiao, N. Gao, Z. Moktadir, M. Kraft, M.J. Starink, J. Micromech. Microeng. 20 (2010) 045029.

8. S. Geißdörfer, A. Rosochowski, L. Olejnik, U. Engel, M. Richert, Int. J. Mater. Form. S1 (2008) 455.

9. N. Warthi, P. Ghosh, A.H. Chokshi, Scr. Mater. 68 (2013) 225.

10. W.J. Kim, S.J. Yoo, H.K. Kim, Scr. Mater. 59 (2008) 599.

11. A. Rosochowski, W. Presz, L. Olejnik, M. Richert, Int. J. Adv. Manuf. Technol. 33 (2007) 137.

12. Y.H. Zhao, Y.Z. Guo, Q. Wei, A.M. Dangelewicz, C. Xu, Y.T. Zhu, T.G. Langdon, Y.Z. Zhou, E.J. Lavernia, Scr. Mater. 59 (2008) 627.

13. M. Furukawa, Y. Iwahashi, Z. Horita, M. Nemoto, T.G. Langdon, Mater. Sci. Eng. A 257 (1998) 328.

14. J. Xu, X. Zhu, L. Shi, D. Shan, B. Guo, T.G. Langdon, Adv. Eng. Mater. (2015), DOI: 10.1002/adem.201400448

15. C. Xu, Z. Horita, T.G. Langdon, Acta Mater. 56 (2008) 5168.

16. Y. Fukuda, K. Oh-ishi, M. Furukawa, Z. Horita, T.G. Langdon, Acta. Mater. 52 (2004) 1387.

17. M. Kawasaki, Z. Horita, T.G. Langdon, Mater. Sci. Eng. A 524 (2009) 143.

18. Y. Iwahashi, Z. Horita, M. Nemoto, T.G. Langdon, Acta. Mater. 46 (1998) 3317.

19. K. Nakashima, Z. Horita, M. Nemoto, T.G. Langdon, Acta. Mater. 46 (1998) 1589.

20. C. Xu, M. Furukawa, Z. Horita, T.G. Langdon, Mater. Sci. Eng. A 398 (2005) 66.

Cite this article as: $\mathrm{Xu}$ J, Wang $\mathrm{C}$, Shan $\mathrm{D}$, Guo B \& Langdon TG: Micro-deformation behavior in micro-compression with high-purity aluminum processed by ECAP. Manufacturing Rev. 2015, 2, 1. 